\title{
Fisher Denklemindeki Risk Primi Parametresinin Durum Uzay Modeli Ve Kalman Filtresi İle Tahmini: Türkiye Örneği
}

\author{
Levent ÖZBEK ${ }^{1}$, Rezzan KAYAK ȘEN ${ }^{2}$ \\ Özet
}

Íktisadi teoriler evrensel olmakla birlikte koşullara, zamana ve toplumlara göre farklı görünümler alır. Bu nedenle yapılan bir analizden elde edilen sonuçların her yerde ve her koşulda geçerli olarak algılanmaması gerekir. Bir ülkede riski artıran bir gelişme bașka bir ülkede aynı etkiyi yaratmayabilir. Gerek faiz oranlarındaki gerekse risk primindeki bu oynakliğın altında yatan şey beklentilerdir ki; ekonomik ilişsiler, farklı ülkelerde çeşitli dönemlerde oldukça değişik görünümler sergileyebilir. Bu çalışmada faizin vade yapısı Beklentiler Hipotezi $(B H)$ açısından ele alınarak zamanla değişen risk primi Kalman filtresi kullanılarak tahmin edilmiştir. Kalman filtresi yaklaşımı, faiz oranındaki değişimlerin oynaklığını, risk primindeki olası kalıcı değişimleri ve üst üste gelen tahmin hatalarını dikkate almaktadır. Çalıșmada Türkiye ekonomisine ait 2002:01-2018:10 dönemi için aylık faiz oranı (TL üzerinden açılan mevduatlara iliş̧in faiz oranı) verilerinden yararlanılmıştır. Çalışmanın en önemli özelliği, Türkiye ekonomisi için risk primini değiştirmeye sebep olan faktörlerin zaman boyunca önceden belirlenmeksizin Kalman filtresi ile nasıl tahmin edeceğimizi sağlamasıdır. Kalman filtresi kullanılarak elde edilen risk primi tahminlerine göre, risk primi bazı dönemlerde pozitif, bazı dönemlerde ise negatif değerler almaktadır. Risk primi, oynaklığın yüksek olduğu dönemlerde negatif, oynaklığın düşük olduğu dönemlerde ise pozitif tahmin edilmiştir. Elde edilen tahmin sonuçları rasyonel yatırımcllara faiz oranlarındaki gelecek değişimlere ait belirsizlikler hakkında önemli ve yararlı bilgiler sunmaktadır.

Anahtar kelimeler:Beklentiler Teorisi, risk primi, zamana göre değișken parametrelerin tahmini, Kalman Filtesi. Jel Kodu: E31, E43, C53, C32.

\section{Estimation Of Risk Premium Parameters In The Fisher Equation By The State Space Model And Kalman Filter: Case Of Turkey}

\begin{abstract}
Statistical theories are universal and come into sight differently with respect to the conditions, time and societies. Therefore, the results obtained from an analysis should not be comprehended as valid for everywhere and in all conditions. A riskincreasing event in a country might have different effects in another country. What underlies the changefulness of interest rates as well as risk premiums is the expectation; thus the economical relations may have quite different appearances for various periods in different countries. In this study, the time-varying risk premium is attempted to be estimated using the Kalman filter and examining the term structure of the interests from the viewpoint of the Expectations Hypothesis (EH). Kalman filter approach takes the changefulness of interest rates, potentially permanent changes of risk premiums and overlapping errors of estimation into consideration. The study has used of the data on monthly interest rates (regarding the TL-based accounts) for the 2002:01-2018:10 period in Turkey's economy. The most important feature of the study is that it allows us to identify how the factors causing changes in risk premiums for Turkey's economy can be estimated in time using the Kalman filter with no predeterminations. According to the risk premium estimates obtained by using the Kalman filter, the risk premium takes positive values in some periods and negative values in other periods. The risk premium is estimated to be negative in high volatility periods and positive in low volatility periods. The results obtained provide rational investors with important and beneficial information about the uncertainties of future changes in the interest rates.
\end{abstract}

Keywords: Expectation Theory, risk premium, estimation of time-varying parameters, Kalman Filter. Jel Codes: E31, E43, C53, C32.

ATIF ÖNERisí (APA): Özbek, L., Kaynak Şen, R. (2022). Fisher Denklemindeki Risk Primi Parametresinin Durum Uzay Modeli ve Kalman Filtresi ile Tahmini: Türkiye Örneği. İzmir İktisat Dergisi. 37(1). 19-33. Doi: 10.24988/ije.750408 ${ }^{1}$ Doç. Dr., Ankara Üniversitesi, Fen Fakültesi, Beşevler / ANKARA, EMAIL: ozbek@science.ankara.edu.tr ORCID: 00000003-1018-3114

2 Dr., T.C. Hazine ve Maliye Bakanlığı, Çankaya/ANKARA. EMAIL: rezzan.ksen@gmail.com ORCID: 0000-0003-26093236 


\section{GíRiș}

Gelecekteki faiz oranlarını tahmin etmek, hem iktisatçıları hem de politika yapıcıları en fazla endișelendiren konulardan birisidir. Faiz oranlarının vade yapısı ile ilgili belirsizlikler akademik araştırmacıların ve uygulayıcıların dikkatini çekmektedir. Getirilerin zamanla nasıl değiștiğini ve oynaklığını anlamak, kamu borcunun finansmanı, reel ekonomik faaliyet ve enflasyon hakkında beklentilerinin oluşumu, menkul değer portföyünün risk yönetimi, faiz oranı türevlerinin değerleri gibi konular hem yatırım sektörlerini hem de para politikasının yürütülmesini etkilediğinden ekonomideki bazı alanlar için gereklidir.

BH, rasyonel yatırımcıların sadece getiri farkını gözlemleyerek faiz oranlarındaki gelecek değişimleri tahmin edilebileceğini ifade etmektedir. Mishkin (1990)'e göre gelecekteki enflasyon farkını tahmin etme yeteneği açısından BH yeniden formüle edilebilir. Çekici olmasına rağmen bu teori oldukça az sayıda ampirik destek bulmuştur. Zamanla değişen vadeli prim ve değişen risk algısı, söz konusu zayıf ampirik kanıtların mantıklı olduğunu savunmuştur. Özellikle, beklenen ve gerçekleşme arasındaki sapmalar büyük olduğunda, yani risk priminin oynaklığında artışın olduğu dönemlerde, doğrusal modeller BH'ni desteklemede başarısız olmaktadır.

Genel olarak doğrusal olmayan modellere (özellikle eşik modellerine) ilgi, genellikle doğrusal modeller tarafından BH'nin reddedilmiş olması gerçeğinden hareket edilerek ortaya çıkmıştır. Tek denklemli modellerde BH'nin ampirik başarısızlığı, Mankiw ve Miron (1986), Fama (1986), Cook ve Hahn (1989), Lee (1995), Tzavalis ve Wickens (1997) çalışmalarında zamanla değişen risk priminin varlığına işaret etmektedir. Ayrıca McCallum (1994 ve 2006), zamanla değișen birinci dereceden otoregresif risk priminin, faiz oranında düzeltmeye izin veren bir para politikası kuralı ile basit bir biçimde bir arada düşündüğü BH'ni doğrulamak için doğrusal modellerin yapısı gereği yetersizliğini göstermiştir.

Yatırımcıların tahvil gibi menkul değerlere yatırım yapma riskini alabilmeleri için risk primine ihtiyaç duydukları bir ortamda, doğru risk priminin hesaplanması oldukça önemlidir. Bu çalışma Kalman filtresinden yararlanılarak, risk priminin değişimine neden olan faktörlerin önceden belirlenmeksizin vade terimini nasıl tahmin edeceğimizi göstermektedir. Bu özellik sayesinde, kısa vadeli faiz oranlarının politik iklim gibi gözlemlenmesi zor olabilen faktörlerden etkilenme olasılığını araştırmaya da yardımcı olmaktadır.

Çalışmanın ilk bölümünde faiz oranları vade yapısına ilişkin beklentiler teorisi açıklanmış, ikinci bölümde konuyla ilgili yapılan ve literatürde yer alan önemli çalışmalara değinilmiş, üçüncü bölümde ise yararlanılan metodoloji, kullanılan veri seti ve analiz sonuçlarına yer verilmiştir. Son olarak sonuç ve değerlendirme kısmında da elde edilen sonuçlar değerlendirilmiştir.

Çalışmanın en önemli özelliği, Türkiye ekonomisi için risk primini değiştirmeye sebep olan faktörlerin zaman boyunca önceden belirlenmeksizin Kalman filtresi ile nasıl tahmin edeceğimizi sağlamasıdır. Kalman filtresi kullanılarak elde edilen risk primi tahminlerine göre, risk primi bazı dönemlerde pozitif, bazı dönemlerde ise negatif değerler almaktadır. Risk primi, oynaklığın yüksek olduğu dönemlerde negatif, oynaklığın düşük olduğu dönemlerde ise pozitif tahmin edilmiștir. Elde edilen tahmin sonuçları rasyonel yatırımcılara faiz oranlarındaki gelecek değişimlere ait belirsizlikler hakkında önemli ve yararlı bilgiler sunmaktadır.

Çalışmada kullanılan Durum-Uzay modeli ve Kalman filtresi yaklaşımın (tahmin yönteminin) kullanılmasının zamana bağlı parametrelerin tahmininde daha etkili olduğu önerilmektedir. Klasik yöntemler parametrelerin sabit olduğu varsayımı üzerine tahmin işlemini gerçekleştirir ki bu her zaman gerçeklikle örtüşmez. Bu nedenle kullanılan bu metodolojinin gerçekliği açıklamada daha etkili olduğunu düşünmekteyiz. 


\section{FAİZ ORANLARI VADE YAPISININ BEKLENTÍLER TEORİSİ}

Faiz oranlarının vade yapısının temel teorisi BH'dir. Bu hipoteze göre, vade sonuna kadar uzun vadeli tahvili elde tutmanın beklenen getirisi, uzun vadeli tahvillerinkine eşit bir toplam vadeye sahip kısa vadeli tahvillerin bir serisine uzatılmasından beklenen getiri ile aynıdır. Uzun vadeli tahvil getirisi, beklenen kısa vadeli oranların ortalamasıdır. Vadeli oran, beklenen gelecek kısa vadeli orandır.

$\mathrm{BH}$, getiri eğrisinin basit ve sezgisel olarak yorumlanmasını sağlasa da, faiz oranı riskini göz ardı eder. Vadeye kadar hesaplanması dıșında, uzun dönemli bir tahvilin nominal getirisi belirsizdir ve yatırımcılar bu risk için bedel (karşılık, tazminat) talep edebilir. "Risk primi”, diğer başka kaynakları ile birlikte BH'den sapmaların bu bedeline karşıllı gelir.

Uzun tahviller için talep edilen bedel, değişken yapılarından dolayı (zamanla her ikisi de değişebilen) hem riskin fiyatı hem de riskin miktarına bağlıdır. Örneğin, sistematik riskin derecesi enflasyon, reel faaliyet ve para politikasına dair belirsizliğin değișen algılarıyla değișebilir. Ayrıca yatırımcılar ekonomik durgunlukta ekonomik canlılığa göre daha fazla riskten kaçınabildiğinden dolayı söz konusu bedel iş çevrimleri ile değişebilir.

Saf BH'nde tüm vadeler için risk primi sıfırdır. Rasyonel beklenti varsayımının ilave edilmesi, $t$ zamanında tüm bilgilerin birbirinden bağımsız ve artıkların ardıșık olarak ilişkisiz olduğu, sıfır ortalamaya sahip elde tutulan dönemin getirisinin aşırı gerçekleștiği saf BH'nin basit bir testini verir. Bu çok makul bir iddiadır, çünkü bir dönem için uzun vadeli tahvili elde tutmanın getirisi ile ilgili belirsizlik vardır ve elde fazla tutmanın getirisi risk için ödülün biçimine bağımlı olmalıdır. Risk için bu ödül "risk (vade) primi"dir.

Faiz oranı ile risk primi arasındaki ilişki, basit bir biçimde aşağıdaki şekilde gösterilmektedir.

Şekil 1: Faiz-Risk Doğrusu

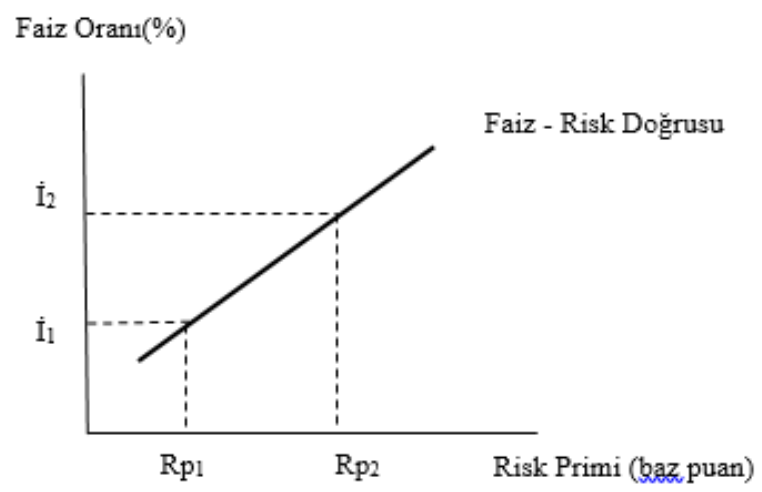

Kaynak: https://www.mahfiegilmez.com/2014/05/faiz-kur-ve-risk-iliskisi.html

Ekonomik, sosyal ve politik alanlar başta olmak üzere çeşitli alanlarda riskleri artan bir ekonomiye borç verenler daha yüksek faiz talep ederler. Risklerin düşürülmesi ya da borçlanmanın azaltılması mümkün değilse faizler yükselecektir. Yukarıda yer alan şekilde de görüldüğü gibi böyle bir durumda faizlerle risk primi aynı yönde hareket edecektir. Riskler artarsa faizler de artacak, riskler düşerse faizler de düşecektir.

BH'ni oluşturan temel varsayımlar:

a) Risk primi zaman boyunca sabittir.

b) Risk primi tahvilin vadesine kadar olan dönemden bağımsızdır. BH ile reel beklentinin bir bileşimi, zamanla sabit (değişmez) vadeli prim ile birlikte varyans eşitsizliğini verir; öyle ki n dönemli tahvilin bir dönem elde tutma getirisinin varyansı, bir dönem güven oranına eșit ya da daha büyük olmalıdır. 
BH'ne ilişkin teori, araştırmacılar tarafından büyük ilgi görmüştür. Campbell (1995) ve Shiller (1990) tarafından yapılan çalışmaların faiz oranları vade yapısının beklenti teorisini reddetmesi, rasyonel beklentileri olan ve risk primi belirleyen ajanların zamanla sabit olduğunu açıklar. Reddetme iki nedenden kaynaklanabilir. Zamanla değişen risk primi reddedilmeye ya da gerçekleştiğinde sapmalı görünen tahmin hataları nedeniyle reddedilmeye neden olmuştur. Bu çalıșmalarda araştırmacıların çoğu, ABD verilerini kullanmıştır. Pesando (1975), Gregory ve Voss (1991) ve Johnson (1993) gibi araştırmacılar BH'ni desteklemek için Kanada hükümeti hazine bonosu ve hazine tahvili verilerini kullanmıștır. İngiltere ve Kanada dışındaki farklı ülkeler için BH'ni inceleyen diğer araştırmacılar Kugler (1996), Hardouvelis (1994) ile Gerlach ve Smets (1997)'dir.

Beklenti hipotezi (BH) beklenen aşırı getirilerin sabit olduğunu kabul eder ki, bu husus ekonomi finans ve para politikası analizlerinde önemli rol oynar. Bu nedenle, çok zor olmasına rağmen $\mathrm{BH}$ araştırmacıların çok yoğun bir şekilde test çalışması yapmasına neden olmuş ve çalışmalar sonucunda da çelişkili sonuçlar elde etmişlerdir. Bu bakımdan literatürde Campbell-Shiller paradoksu (CSP) olarak bilinen çelişkili sonuçları ile ön plana çıkmaktadır. Campbell ve Shiller'in 1991 yılında yayımladıkları önemli çalışmada vardıkları sonuç; BH'nin hemen her zaman reddedilmesine rağmen, sonuçlar uygulanan test yöntemlerine bağlı olarak önemli oranda değișim göstermiştir. Bu bakımdan, kısa vadeli faiz oranlarındaki uzun dönemli değişimler ile uzun dönem kısa dönem faiz oranları arasındaki farka uygulanan regresyon analizi yapan çalışmalar önemli yer tutmaktadır.

\section{LİTERATÜR ÖZETI}

Genel olarak ampirik çalışmalardan elde edilen sonuçlar kullanılan metodolojiye (çalışmanın yürütüldügü dönem, ülke ve faiz oranlarının vade profili) göre farklılaşabilmektedir. BH'nin testi ile ilgilenen mevcut literatürde 3 temel konunun belirgin olarak incelendiği görülmektedir:

1) Zamanla değișen risk primi, ekonomik olarak anlamlı ve ilgili görünmektedir.

2) Zamanla değişen risk primi, ekonomik faktörler ve diğer gözlemlenemeyen faktörler tarafından açılklanabilir.

3) Guillen ve Tabak (2008)'e göre, çalışma konusu ülkede belirli tahvil piyasası koşulları ülkeler arasında böyle değişken davranışların neden gözlemlendiğini açıklayabilmektedir.

\subsection{0 Öncesi Literatür}

Shiller (1990), Pesando (1975), Mankiw ve Summers (1984) ve Nelson (1972)'un faiz oranları vade yapısının zamanla değişen risk priminin belirlenmesi için yürüttüğü çalışmalarda işsizlik oranları, getiri eğrileri ve faiz oranlarının seviyesi gibi değişkenlerin ilk evresine dikkat etmiştir. Günümüzdeki çalışmalarda, beklenti teorisinin reddedilmesiyle ilgili sezginin açıklanmasına yardımcı olan așırı getirilerin koşullu varyansları kullanılmaktadır. Engle (1982), Engle, Lilien ve Robbins (1987) bu çalışmalara örnektir. Breeden (1986) ve Campbell (1987) gibi araştırmacılar, düşüncelerini denge varlık fiyatlandırma modellerine yöneltmişlerdir; çünkü BH'nin başarısız olduğunu ve faiz oranlarının vade yapısındaki risk priminin zamanla değiştiğini fark ettiler. Yatırımcılar tahvil gibi menkul kıymetlere yatırım yapma riskini alabilmek için risk primine ihtiyaç duyarlar. Risk primini anlamak yatırımcıların sayısını azaltabilir ve risk primini büyütmek banka ve mali şirketlerinin çöküşüne ve zararına yol açabilir. Vade yapısının makroekonomik belirleyicilerinin araştırılması, hem yatırımcılar hem de firmalar için doğru risk priminin hesaplanmasına yardım edecektir.

Heath, Jarrow ve Merton'un modeline göre, Vasicek, Ho ve Lee, Hull ve White, Black Derman ve Toy (BDT) ve Black-Karasinki'nin çalışmalarında yer alan çeşitli ekonomik modellere rağmen, faiz 
oranları son derece oynak ve öngörülemezdir. Doğru bir tahmin yapabilmek için bu değişimlere neden olan makroekonomik değişkenler araştırılmalıdır.

Para politikasının vade yapısı üzerine etkisine ve getiri farkına ilişkin birçok araştırma yapılmıştır. Araştırmacıların çoğu, vade yapısı üzerinde aşırı geri dönüşün koşullu varyans üzerindeki etkisini ihmal etmektedir. Dolayısıyla, getiri farkı ile aşırı geri dönüşün koşullu varyansının, faiz oranları vade yapısı üzerindeki para politikasının birleşik etkisini görmek çok önemlidir.

Engle vd. (1987) Arch-M modeli olarak bilinen metodolojiyi risk primini belirlemek için kullanmıştır. $\mathrm{Bu}$ metodolojide aşırı getirinin koşullu varyansı, mevcut risk primini belirlemektedir. 1960-1984 dönemi için 3 ve 6 aylık ABD hazine bonosu faiz oranına ait çeyrek dönemli veriler kullanarak modellerini test etmişler ve belirsizlik altında piyasa oyuncularının algısıyla risk priminin zaman boyunca sistematik bir biçimde değiştiği sonucuna varmışlardır.

\subsection{Sonrası Literatür}

Beklenti teorisinin reddedilmesiyle ilgili sezginin açıklanmasına yardımcı olan aşırı getirilerin koşullu varyanslarının kullanıldığı çalışmalar arasında Engle, Ng ve Rothschild (1990) ve Lee (1995) yer almaktadır.

Iyer (1997) ABD için tahmin edilen primlerde önemli değişimler ile zaman boyunca bu tahminlerdeki oynaklıkların anlamlı biçimde devam ettiğini tespit etmiştir.

Kozicki ve Tinsley (2002) risk priminin politika kuralı tanımlamasına ve politika oranı belirsizliğine nasıl bağlı olabileceğini göstermiştir. Daha saldırgan politika kuralının risk priminde ekonomik olarak önemli bir artışı içerdiğini bulmuşlardır.

Arize vd. (2002) gelişmiş ve gelişmekte olan 19 ülke için BH'ni vektör hata düzeltme modeli ile test etmiş ve İngiltere dışında BH'ni destekleyen kanıtlar bulmuşlardır.

Tabak ve Andrade (2003) Brezilya faiz oranlarının dönem yapısını 1995-2001 dönemi için BH'ni test etmiş ve reddedilmesine ilişkin kanıt bulmuştur. Ayrıca getiri eğrisindeki risk primi ile faiz oranlarının oynaklığının pozitif ilişkili olduğunu göstermişlerdir. Lima ve Issler (2003) Brezilya için BH'ni bugünkü değer yaklaşımını kullanarak test etmişler ve hipotezi kısmen reddetmişlerdir. Brito vd. (2004) de farklı bir metodoloji kullandığı Brezilya ekonomisi için BH’ni reddetmişlerdir.

Gravele ve Morley (2005), Kanada için ekonomik değişkenler ile risk primi arasındaki ilişkiyi araştırmış ve faiz oranlarındaki oynaklık ve diğer makroekonomik değişkenler ile risk primi arasında pozitif ilişkinin varlığına ilişkin güçlü kanıtlar elde etmişlerdir. Ayrıca gözlemlenemeyen değişkenlerin, ekonomik temellerin yanı sıra vade teriminin açıklanmasında önemli bir rol oynadığını bulmuşlardır.

\subsubsection{Konu ile ilgili Türkiye Ekonomisi Üzerine Yapılmış Çalışmalar}

Alper vd. (2004), Türkiye'de 1992-2004 döneminde aylık getiri eğrilerini tahmin etmek amacıyla McCulloch'un modeli ile Dinamik Nelson-Siegel Modelini örnek içi ve dışı analizleri karşılaştırmak için kullanmıştır. McCulloch yönteminin örnek içi özelliklerinin, Nelson-Siegel yönteminin ise örnek dışı özelliklerinin daha üstün olduğuna dair kanıt bulmuşlardır.

Kaya (2010) çalışmasında, 1993:01-2009:02 dönemi aylık faiz oranı ile enflasyon, büyüme, kapasite kullanım oranı, döviz kuru, bütçe açığı, borçlanma, sermaye hesabı ve cari işlemeler dengesinden oluşan makroekonomik değiş̧kenleri kullanarak Türkiye'de faiz oranı vade yapısı ile makroekonomik değişkenler arasındaki ilişkiyi araştırmıştır. Verim eğrisinin şeklini belirleyen iki temel değişkenin enflasyon ve döviz kuru olduğunu tespit etmişlerdir. 
Arslan (2012) çalışmasında faiz oranlarının vade yapısını açıklamada kullanılan BH ve bunun Türkiye sabit getirili menkul kıymet piyasasında 3 Ocak 2003-21 Haziran 2010 döneminde 8 farklı vadedeki kuponsuz devlet tahvilleri faiz oranları için test etmiştir. Türkiye ekonomisinde sabit getirili menkul kıymet piyasasında kısa vadeli faizlerdeki değişim, daha uzun vadelerdeki tahvil faizlerini etkilediği sonucunu elde etmiştir.

Tüysüzoğlu (2013) çalışmasında, Dinamik Nelson-Siegel Modeli ile Geliştirilmiş Dinamik NelsonSiegel Modeli kullanarak Türkiye için getiri eğrilerini modellemiş ve bu modellerden elde ettiği eğrileri kullanarak getirilerin gelecekte alacağı değerleri tahmin etmiştir. Dinamik Nelson-Siegel Modelinden elde edilen getiri eğrisi modelinin öngörüsü diğerine göre daha iyi olduğu sonucuna ulaşmıştır.

Demirel (2014) çalışmasında Türk Lirası faiz oranı vade yapısını bootstrapping yöntemi ve en küçük kareler (EKK) metodu kullanılarak tahmin edilmiştir. Çalışmada sabit kuponlu tahvil ve kuponsuz bonolar kullanılarak ilgili güne ait Türk Lirası verim eğrisinin tahmin edilmesi amaçlanmıştır. Teorik olarak her bir vadeye tekabül eden bir faiz oranı bulunduğu kabul edilmekle birlikte uygulamada bu sayıda kuponsuz bono işlem görmediği için bu durumu gözlemek mümkün olamamaktadır. Bu nedenle gözlenen verilerden yola çıkılarak istenen vadeler için faiz oranları tahmin edilmektedir. Diğer bir ifadeyle piyasada oluşan mevcut faiz oranlarına en iyi uyumu sağlayan teorik bir faiz oranı seti oluşturulmaktadır. Bu amaçla çeşitli yöntemler geliştirilmiş olup, bu çalışmada 31 Aralık 2013 tarihli Türk Lirası verim eğrisi bootstrapping yöntemi ve ardından gerçekleştirilen EKK analiziyle elde edilmiştir. Analiz sonuçları bootstrapping yöntemi ve EKK analizi sonucunda hesaplanan parametrelerin istatistiki olarak anlamlı olduğunu göstermiştir.

\section{METODOLOJİ (MODEL)}

Faiz oranlarının vade yapısı ile ilgili teorilerden en yaygın olarak bilinen BH'nde uzun dönemli faiz oranı, gelecekte beklenen kısa dönemli faizlerin uzun dönemli ortalamasına zamanla değișmeyen risk priminin eklendiği varsayılmaktadır.

$$
R_{t}^{(n)}=\frac{1}{k} \sum_{i=0}^{k-1} E_{t} R_{t+m i}^{(m)}+\psi_{k}
$$

Eşitlik (1)'de;

$R_{t}^{(n)}$ : n dönemli uzun vadeli faiz oranını,

$R_{t}^{(m)}:$ m dönemli kısa vadeli faiz oranını,

$k=n / m:$ tamsaylyl

$E_{t}:$ d dönemine ait ekonomik ajanların bilgi setine ilişkin koşullu beklentiyi,

$\psi_{k}$ : sabit risk primini ifade etmektedir.

BH kabul ediliyorsa, risk primi sabittir ve mevcut oranlar ile gelecekte beklenen oranlar arasındaki ilişkiyi anlamak kolaydır. Sabit risk primi dışında, mevcut uzun dönem faiz oranı gelecek kısa dönem faiz oranlarının sapmasız bir tahmin edicisidir. Risk primi zaman boyunca değişirken, beklenen gelecek kısa dönem faiz oranlarının gözden geçirilmesiyle uzun dönem faiz oranındaki değişimleri ayırt etmek zordur. 


\subsection{Risk Primi Tahmin Yöntemlerine Genel Bakış}

\subsubsection{Sabit Risk Primi}

Eşitlik (1) aşağıdaki gibi yeniden yazılabilir:

$f_{t, t+k}=E_{t}\left(s_{t+k}\right)+\rho$

$f_{t, t+k}: \mathrm{t}$ döneminde gözlemlenen vadeli $\mathrm{t}+\mathrm{k}$ dönemine ait faiz oranını ifade etmektedir.

Beklentilerin rasyonel olduğu varsayımıyla;

$s_{t+k}=E_{t}\left(s_{t+k}\right)+\varepsilon_{t, t+k}$

Risk primi;

$\rho=f_{t, t+k}-s_{t+k}+\varepsilon_{t, t+k}$

biçiminde ifade edilebilir. Eşitlik (4)'e göre gözlem sayısı fazla olduğunda ortalama öngörü hatası $\varepsilon_{t, t+k}$ sıfıra yaklaşacağından, gelecek döneme ilişkin ortalama sapma $\left(f_{t, t+k}-s_{t+k}\right)$ ortalama risk primine yaklaşacaktır. Bu yöntem ortalama risk seviyesini ölçmek için basit bir yol olmasına rağmen, zamanla değişen primini yakalayamayabilir; çünkü yöntem beklentilerin sapmasızlığı varsayımına dayanmaktadır.

\subsubsection{Kalman Filtresi Yaklaşımını Kullanarak Zamanla Değişen Risk Priminin Tahmini}

Eşitlik (2) kullanılarak, gerçekleşen ileriye yönelik sapma, risk primi terimi ve tahmin hatası olarak ayrıştırılabilir. Ayrıca, risk primini otoregresif süreç olarak yazarsak, gerçekleşen ileriye yönelik sapmayı ve risk primini durum uzay gösterimi ile aşağıdaki gibi elde edebiliriz:

$$
f_{t, t+k}-s_{t+k}=\rho_{t}+v_{t+k}
$$

Burada $v_{t+k}=\varepsilon_{t, t+k}$ 'dır.

$$
\rho_{t}=\alpha+\phi \rho_{t-1}+u_{t}
$$

Bu sistem, normal dağılımlı beyaz gürültü süreçlerine sahip ve hata terimlerini sağlayan Kalman filtresi ile tahmin edilebilmektedir. Durum-Uzay modelleri ve Kalman Filtresi için detaylı bilgilere Özbek (2017) ve Öztürk (2015) kaynaklarına bakılabilir. Eșitlik (6) gözlemlenemeyen durum değișkeninin değișimini tanımlarken, eşitlik (5) gözlem denklemi olarak ifade edilir. Sadece gözlem değişkeni (örneğin burada gerçekleșen ileriye yönelik sapma) gözlemlenir ve durum değişkeni için bir otoregresif süreç varsayılırsa, Kalman filtresi yardımıyla $\rho_{t}$ (gizli ya da görünmeyen durum değişkeni) tahmin edilebilir. Bu amaçla, $\mathrm{t}+\mathrm{k}$ dönem ileri vadeli faiz oranı durumunda, tahmin hatası terimi olan $v_{t+k}$, aşağıdaki MA(k-1) sürecini izleyecektir.

$v_{t+k}=v_{t+k}+v_{t+k-1}+\ldots+v_{t+1}$

\subsection{Veri Seti, Ekonometrik Yöntem ve Analiz}

Bu çalışmada Türkiye ekonomisinde 2002-2018 dönemi için faiz oranlarının vade yapısındaki risk priminin zamanla gösterdiği değişim Kalman filtresi tahmin yöntemi kullanılarak araştırılmıștır. 2002:01-2018:10 dönemine ait aylık faiz oranı (TL üzerinden açılan mevduatlara ilişkin faiz oranı) verilerinden yararlanılmıştır. Söz konusu veriler, TCMB'nin internet sayfalarındaki veri dağıtım sisteminden (EVDS) elde edilmiştir. 
Gravelle ve Morley (2005)'in de ifade ettiği üzere bu çalışmada Kalman filtresinin kullanılmasının iki temel sebebi vardır:

1) Geleneksel doğrusal regresyon metotları kullanarak BH'ni test eden kısa dönem Kanada faiz oranlarına ait mevcut çalışmalarda, güçlü bir şekilde çelişkili sonuçlar elde edilmiştir. Özellikle Gravelle vd. (1999) ve Hejazi vd. (2000) gelecekteki faiz oranının sapmasızlığını reddederken, Paquette ve Streliski (1998) bunu destekleyen kanıtlar bulmuştur. Kalman filtresi yaklaşımı araştırmacılara bu konuda yeni bir bakış açısı sağlamaktadır.

2) BH'nin başarısızlığı bilindiğinde Durum-Uzay modeli ve Kalman filtresi yaklaşımı, risk primini değiștirmeye sebep olan faktörlerin zaman boyunca önceden belirlenmeksizin vade terimini nasıl tahmin edeceğimizi sağlar. Bu özellik kısa vadeli faiz oranlarının politik iklim gibi gözlemlenmesi zor olabilen faktörlerden etkilenme olasılığını araştırmak için özellikle yararlı olabilmektedir. Bu özellik ayrıca vade yapısı biçiminin belirlenmesinde zamanla değişen risk priminin göreceli önemi, faiz oranındaki oynaklık ile diğer ekonomik ve politik faktörlerdeki değişimlerle açıklanabilen risk primindeki hangi değişimleri kapsadığı, risk priminin hiç negatif olup olmadığı ve risk priminin vade yapısı içerisinde benzer biçimde davranıp davranmayacağı hakkında ilginç soruları yanıtlamamıza da yardımcı olmaktadır. Sonuçta risk priminin bu tanımı, BH’nin başarısız olup olmadığının basit bir biçimde belirlenmesi kadar önemlidir.

Grafik 1: TL Üzerinden Açılan Mevduatlara İlişkin Aylık Faiz Oranı (\%)

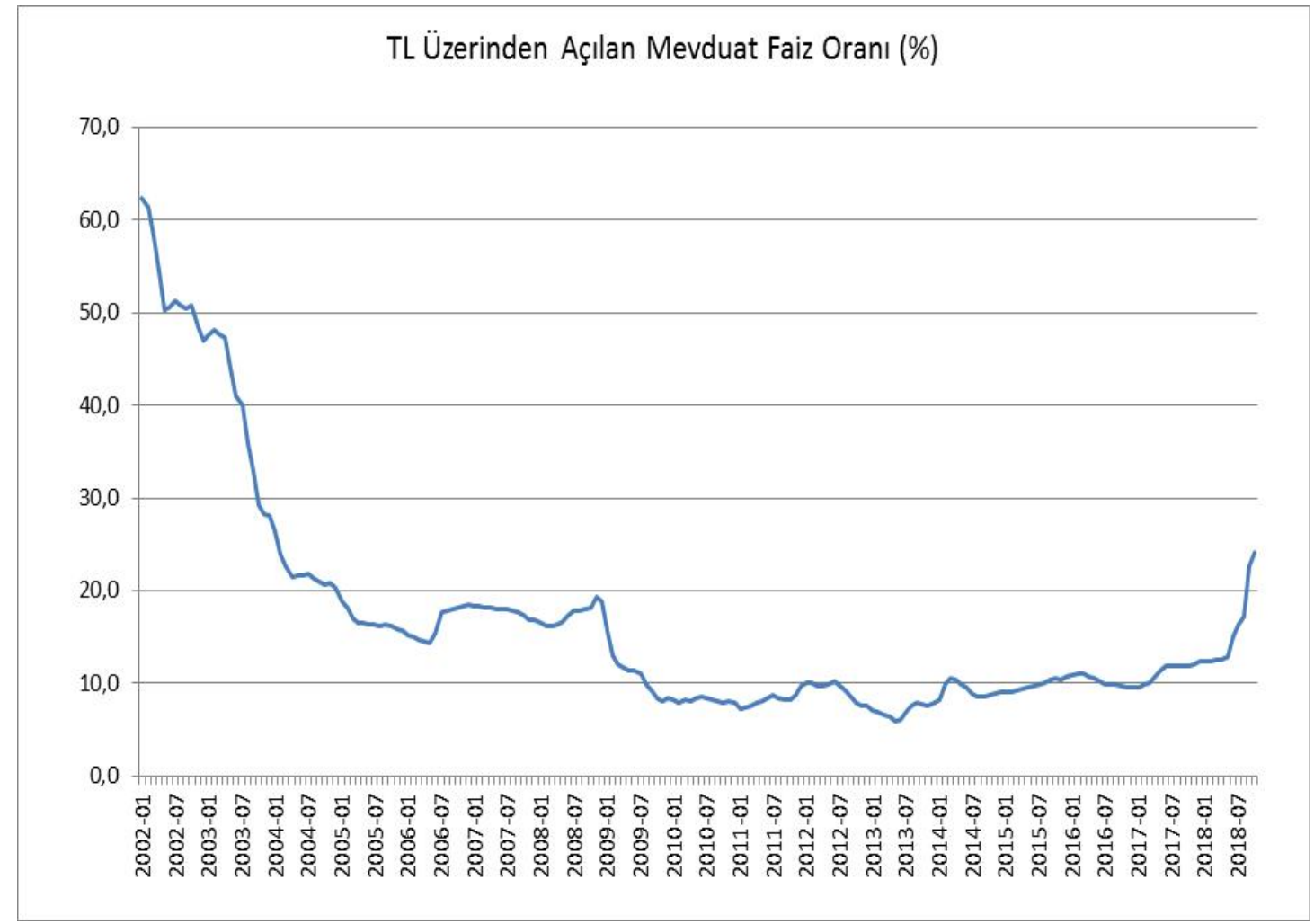

Kaynak: TCMB, EVDS.

Yukarıdaki grafikte 2002-2018 dönemine ilişkin aylık faiz oranlarının gelişimi yer almaktadır. Söz konusu dönem boyunca faiz oranlarının dalgalı bir seyir izlediği ve oynaklığının oldukça fazla olduğu görülmektedir. Grafikten de görüleceği üzere faiz oranlarının genel eğiliminin aşağı yönlü olduğu anlaşılmaktadır. Gerek faiz oranlarındaki gerekse risk primindeki bu oynaklığın altında yatan şey beklentilerdir ki ekonomik ilişkiler farklı ülkelerde, çeșitli dönemlerde oldukça değişik görünümler 
sergileyebilmektedir. Geleceğe ilişkin beklentiler de mevcut görünümü daha da karmaşık bir hale getirebilmektedir.

Bir önceki bölümde açıklanan kalman filtresi kullanılarak faiz oranına ilişkin zamanla değişen risk primi tahmin edilmiştir. Elde edilen sonuçlara ilişkin tahminler ile gerçekleşen veriler aşağıdaki grafikte gösterilmiştir.

Grafik 2: Kalman Filtresi ile Zamanla Değișen Risk Primi Tahmin Sonucu

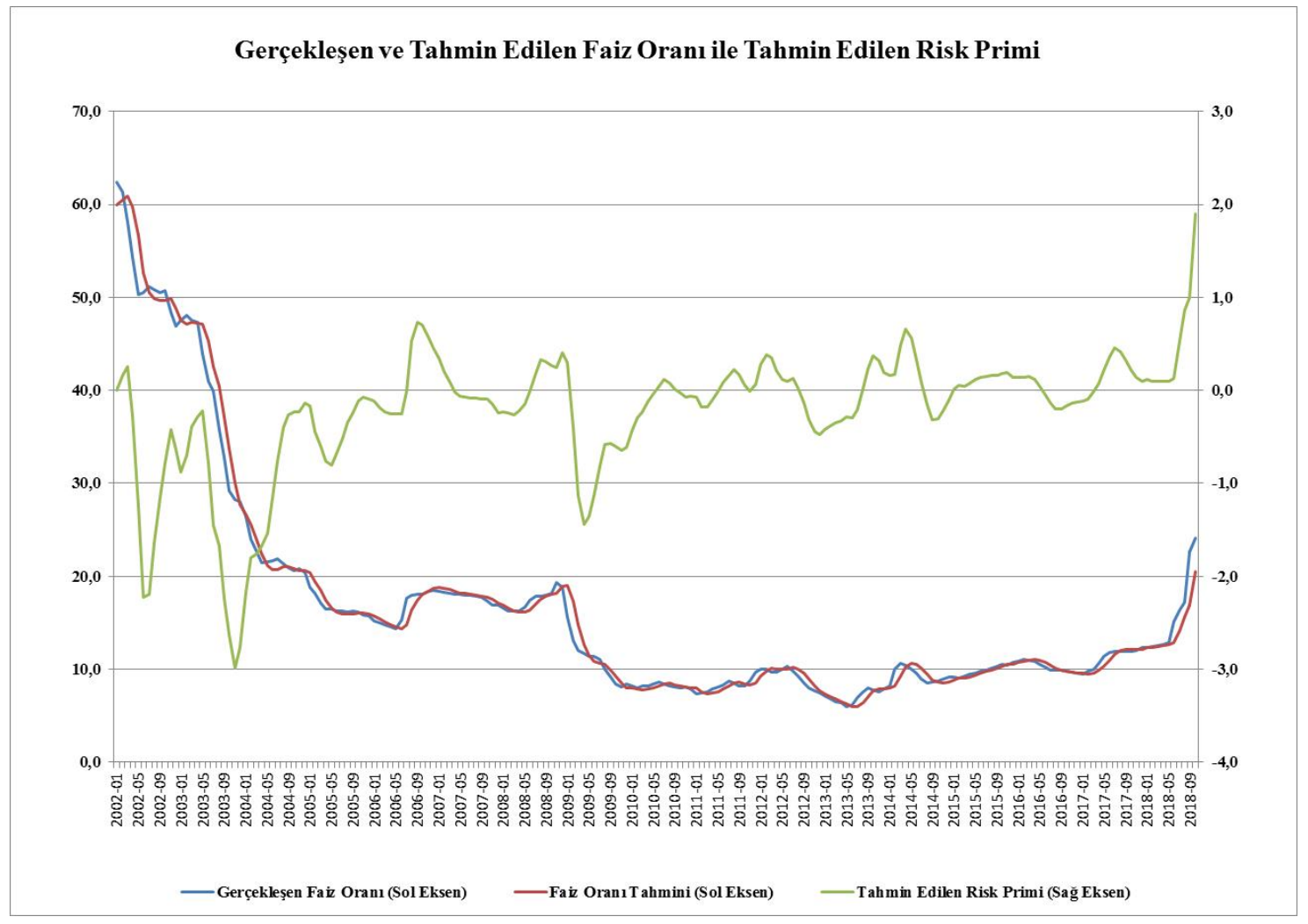

Grafik 2'de tahmin edilen risk priminin bazı dönemlerde pozitif, bazı dönemlerde ise negatif değerler aldığı görülmektedir. Türkiye ekonomisinin genel yapısına bakıldığında, bu durum şaşırtıcı olmamaktadır. Ülke ekonomisindeki sorunlar nedeniyle çeşitli dönemlerde yoğun bir biçimde fon çıkışları faiz oranlarında artışa yol açmış; bu gelişmeler de risk priminin negatif olarak gerçekleşmesine sebep olmuştur.

Lutz (1940)'a kadar uzanan geleneksel görüșe göre, risk primi daima pozitiftir ve vadeye göre artmaktadır. Elde ettiğimiz bulgu ise Modigliani ve Sutch (1966)'ın “bireylerin farklı tercihli yatırım dönemlerinde ya da ortamda daha uzun vadede borç verme ve daha kısa vadede borç almada daha güçlü tercihleri olan piyasa katılımcılarının olması durumunda negatif risk priminin olabilirliğine yol açtı̆̆ı" biçiminde ifade edilen alternatif görüşünü destekler niteliktedir.

\section{SONUÇ VE DEĞERLENDİRME}

Finans teorisinin en önemli konularından biri olan risk ile riskin temel bir göstergesi niteliğindeki oynaklığın modellenmesi ve tahmini araştırmacıların üzerinde yoğunlaștığı bir konudur. Risk zaman içerisinde değişebildiğinden, farklı zamanın riskinin de farklı olabileceği gerçeği hesaplamalarda dikkate alınmalıdır. 
Oynaklıklara yapısal kırılmaların da etki etmesi kullanılan analiz yöntemleri üzerinde olumsuz etkiler yaratacağından, geleneksel yaklaşımlara dayalı analizlerde beklenen sonuçlar elde edilememektedir.

Bu çalışmada faizin vade yapısı BH açısından ele alınarak zamanla değișen risk primi Kalman filtresi kullanılarak tahmin edilmiştir. Kullanılan bu yöntem sayesinde, risk priminin değişmesine sebep olan faktörlerin zaman içerisinde önceden belirlenmeksizin tahmini elde edilebilmektedir. Elde edilen risk primi tahmini, piyasa katılımcıları ve politika yapıcılarının enflasyon beklentileri ile risk algılamaları açısından önemli bilgiler içermektedir.

Çalışmada Kalman filtresi kullanılarak elde edilen risk primi tahminleri bazı dönemlerde pozitif, bazı dönemlerde ise negatif değerler almaktadır. Ekonomik büyümenin yaşandığı dönemlerde finans piyasalarındaki riskte yaşanan artışlar, yatırımcıların ilave risk primi karşılığında yatırımlarına devam etmelerine engel olmamaktadır (pozitif risk primi). Ekonomik büyümede önemli azalmaların yaşandığı dönemlerde ise risk seviyesinin artması nedeniyle yatırımcılar hızlı bir biçimde alternatif yatırım araçlarına yönelmektedir (negatif risk primi). Yatırımcı riskin pozitif olduğu dönemlerde daha yüksek riske sahip yatırım araçları için daha yüksek bir getiri talep edebilirken; riskin negatif olduğu dönemlerde ise riskli yatırım araçları daha az risklilere göre negatif risk primine daha duyarlı olacağından, risk arttıkça daha düşük getiri imkanı elde edebileceklerdir.

Finansal piyasalarda görülen büyük oynaklıklar nedeniyle piyasa oyuncuları, oluşan yeni duruma daha hızlı bir biçimde uyarlanma eğilimindedir. Gerek faiz oranlarındaki gerekse risk primindeki bu oynaklığın altında yatan șey beklentilerdir ki ekonomik ilişkiler farklı ülkelerde, çeşitli dönemlerde oldukça değişik görünümler sergileyebilmektedir. Geleceğe ilişkin beklentiler de mevcut görünümü daha da karmaşık bir hale getirebilir.

Çalışılan alanda belirsizliklerin hüküm sürmesi ile birlikte konunun ekonomik, sosyal, politik ve davranışsal boyutlar içermesi tek bir hipotezin kesinlikle doğru olma olasılığını oldukça azaltmaktadır.

Çeşitli nedenlerden dolayı geleneksel yaklaşımlara dayalı analizlerde beklenen sonuçlar elde edilemediğinden çalışmada kullanılan Durum-Uzay modeli ve Kalman filtresi tahmin yönteminin kullanılmasının bu tip zamana bağlı parametrelerin tahmininde daha etkili olduğu önerilmektedir. 


\section{KAYNAKÇA}

Akıncl, Ö., Gürcihan, B., Gürkaynak, R. ve Özel, Ö. (2006). Devlet İç Borçlanma Senetleri İçin Getiri Eğrisi Tahmini, Araştırma ve Para Politikası Genel Müdürlüğü Çalışma Tebliği, No: 06/08, Ankara.

Arslan, M. (2012). Faiz Oranlarının Vade Yapısı, Beklenti Hipotezinin Türk Sabit Getirili Menkul Kıymet Piyasasında Test Edilmesi, İ̧̧letme Araştırmaları Dergisi, 4(3), 5-19.

Alper, C.E., Akdemir, A. and Kazimov, K. (2004). Estimating the Term Structure of Government Securities in Turkey, Boğaziçi University Research Papers: ISS/EC-2004-03.

Arize, A.C., Malindretos, J. and Obi, Z.I. (2002). Long- and Short-Term Interest Rates in 19 Countries: Tests of Cointegration and Parameter Instability, Atlantic Economic Journal, 30, 105-119.

Breeden, D. (1986). Consumption, Production, Inflation and Interest Rates: A Synthesis, Journal of Financial Economics, 16, 3-39.

Brito, R.D., Duarte, A.J.M.A. and Gullien, O.T.C. (2004). Overreaction of Yield Spreads and Movements of Brazilian Interest Rates, Brazilian Review of Econometrics, 24(1), 1-56.

Campbell, J.Y. (1987). Stock Returns and the Term Structure, Journal of Financial Economics, 18, 373399.

Campbell J.Y. (1995). Some Lessons from the Yield Curve, The Journal of Economic Perspectives, 9(3), 129-152.

Cook T. \& Hahn, T. (1989). The Effect of Changes in the Federal Funds Rate Target on Market Interest Ratesin the 1970s, Journal of Monetary Economics, 24, 331-351.

Demirel, Y. (2014). Faiz Oranı Vade Yapısı: Türk Lirası Faiz Oranları Üzerinde Bir Çalışma, Bankacılar Dergisi, 90, 51-67.

Engle R.F. (1982). Autoregressive Conditional Heteroscedasticity with Estimates of the Variance of United Kingdom Inflation, Econometrica, 50, 987-1007.

Engle, R., Lilien, D. and Robins, R. (1987), Estimating Time-Varying Premia In The Term Structure: The ARCH-LM Model, Econometrica, 55, 391-407.

Engle, R., Ng, V. and Rothschild, M. (1990). Asset Pricing with a Factor ARCH Covariance Structure: Empirical Estimates for Treasury Bills, Journal of Econometrics, 45, 213-238.

Fama, E.F. (1996). Term Premiums and Default Premiums in Money Markets, Journal of Financial Economics, 17, 175-196.

Gerlach, S. \& Smets, F. (1997). The Term Structure of Euro-Rates: Some Evidence in Support of the Expectation Hypothesis, Journal of International Money and Finance, 16(2), 305-321.

Gravelle, T., Muller, P. and Stréliski, D. (1999). Towards a New Measure of Interest Rate Expectations in Canada: Estimating a Time-Varying Term Premium In Information in Financial Asset Prices, Proceedings of a Conference Held by the Bank of Canada, 179-216.

Gravelle, T., \& Morley, J.C. (2005). A Kalman Filter Approach To Characterizing The Canadian Term Structure of Interest Rates, Applied Financial Economics, 15, 691-705. 


\section{L. Özbek - R. Kayak Șen \\ İzmir Íktisat Dergisi / İzmir Journal of Economics \\ Yll/Year: 2022 Cilt/Vol:37 Sayl/No:1 Doi: 10.24988/ije.750408}

Gregory, A. \& Voss, G. (1991). The Term Structure of Interest Rates: Departures from Time-Seperable Expected Utility, Canadian Journal of Economics, 24, 923-939.

Guillen, 0.T. \& Tabak, B.M. (2008). Characterizing the Brazilian Term Structure of Interest Rates, Working Paper The Banco Central do Brasil, 1-20.

Hardouvelis, G.A. (1994). The Term Structure Spread and Future Changes in Long and Short Rate in the G7 Countries - Is There a Puzzle?, Journal of Monetary Economics, 33, 255-283.

Hejazi W., Lai, H. and Yang, X. (2000). The Expectations Hypothesis, Term Premia, and the Canadian Term Structure of Interest Rates, Canadian Journal of Economics, 33, 133-148.

Iyer, S. (1997). Time-Varying Term Premia And The Behavior Of Forward Interest Rate Prediction Errors, Journal of Financial Research, 20, 503-507.

Johnson, S. (1993). Private Sector in Poland: A Small-Scale Survey, The World Bank, Washington D.C. Mimeo.

Kaya, H. (2010). Term Structure of Interest Rate And Macroeconomic Variables: The Turkish Case, International Journal of Economics And Finance Studies, 2(1), 77-85.

Kozicki, S. \& Tinsley, P.A. (2002). Term Premia: Endogenous Constraints On Monetary Policy, Working Paper Federal Reserve Bank of Kansas City, 02-07.

Kugler, P. (1996). The Term Structure Of İnterest Rates And Regime Shifts: Some Empirical Results, Economics Letters, 50, 121-126.

Lee, S.S. (1995). Macroeconomic Sources of Time-Varying Risk Premia in the Term Structure of Interest Rates, Journal of Money, Credit and Banking, 27(2), 549-569.

Lima, A.M. \& Issler, J.V. (2003). A hipótese das expectativas na estrutura a termo de taxa de juros no Brasil: uma aplicação de modelos de valor presente, Revista Brasileira de Economia, 57, 873898.

Mankiw, N.G. \& Miron, J. (1986). The Changing Behavior of The Term Structure of Interest Rates, Quarterly Journal of Economics, CI, 211-228.

Mankiw, N.G. \& Summers, L.H. (1984). Do Long-Term Interest Rates Overreact to Short-Term Interest Rates?, Brookings Pagers on Economic Activity, 1, 223-242.

McCallum, B.T. (1994). Monetary Policy and the Term Structure of Interest Rates, NBER Working Paper, 4938, 1-26.

McCallum, B.T. (2006). Monetary Policy and the Term Structure of Interest Rates, Federal Reserve Bank of Richmond Economic Quarterly, 91(4), 1-21.

Mishkin, F. S. (1990). The Information in the Longer Maturity Term Structure About Future Inflation, The Quarterly Journal of Economics, 105(3), 815-828.

Nelson, C.R. (1972). The Term Structure Of Interest Rates. Basic Books, New York.

Paquette, J.Y. \& Stréliski, D. (1998). The Use of Forward Rate Agreements in Canada, Bank of Canada Review (Spring), 57-71.

Pesando, J.E. (1975). Determinants of Term Premiums in the Market for United States

Treasury Bills, The Journal of Finance, 30, 1317-1327. 
Pesando, J.E. (1978). On The Efficiency of The Bond Market: Some Canadian Evidence, Journal of Political Economy, 86, 1057-1076.

Shiler, R.J. (1979). The Volatility of Long-Term Interest Rates and Expectations Models of the Term Structure, Journal of Political Economy, 87, 1190-1219.

Shiller, R.J. (1990). The Term Structure of Interest Rates (Ed. B. Friedman and F.H. Hahn), Chapter 13 of Handbook of Monetary Economics, Elsevier Science, Amsterdam.

Tabak, B.M. \& Andrade, S.C. (2003). Testing the Expectation Hypothesis for Brazilian Term Structure of Interest Rates, Revista Brasileira de Finanças, 1, 19-44.

Tüysüzoğlu, U. (2013). Türkiye Devlet İç Borçlanma Senetleri Getiri Eğrilerinin Geliştirilmiş Dinamik Nelson-Siegel ve Zaman Serisi Modelleri İle Öngörü Performanslarının Karşılaştırılması, TCMB Uzmanlık Tezi, Ankara.

Tzavalis, E. \& Wickens, M.R. (1997). Explaining The Failures Of The Term Spread Models of The Rational Expectation Hypothesis of The Term Structure. Journal of Money, Credit, and Banking, 29, 364-380.

Özbek, L. (2017). Kalman Filtresi, Akademisyen Kitabevi.

Öztürk, F. ve Özbek, L. (2015). Matematiksel Modelleme ve Simülasyon, Pigeon Yayıncllık. 


\section{EXTENDED ABSTRACT}

\section{Estimation Of Risk Premium Parameters In The Fisher Equation By The State Space Model And Kalman Filter: Case Of Turkey}

\section{Introduction}

The modeling and estimation of risk, which is one of the most important issues of finance theory, and volatility, which is a basic indicator of risk, is a subject that researchers focus on. Underlying this volatility in both interest rates and risk premium are expectations. Economic relations can show quite different appearances in different countries at various periods. Since the risk can change over time, the fact that the risk of different time can also be different should be taken into account in the calculations.

Investors need a risk premium to take the risk of investing in securities such as bonds. Researching the macroeconomic determinants of the maturity structure will help calculate the right risk premium for both investors and firms.

Calculating the right risk premium is very important in an environment where investors need a risk premium to take the risk of investing in securities such as bonds. This study shows how to estimate the maturity term without predetermining the factors that cause the variation of the risk premium, using the Kalman filter.

It is suggested that the State-Space model and Kalman filter approach (estimation method) used in the study are more effective in estimating time-dependent parameters. Classical methods perform the estimation on the assumption that the parameters are constant, which does not always coincide with reality. For this reason, we think that this methodology used is more effective in explaining reality.

\section{Data Set and Method}

In this study, the change in the risk premium in the maturity structure of interest rates for the 20022018 period in the Turkish economy was investigated by using the Kalman filter estimation method. The monthly interest rate (interest rate for deposits opened in TL) for the period 2002:01-2018:10 was used. The said data was obtained from the data distribution system (EVDS) on the CBRT's web pages.

In this study, the maturity structure of the interest rate is handled in terms of the Expectations Hypothesis (EH), and the time-varying risk premium is estimated using the Kalman filter. The Kalman filter approach takes into account the volatility of changes in the interest rate, possible permanent changes in the risk premium, and overlapping estimation errors.

Knowing the failure of EH, the State-Space model and the Kalman filter approach allow us to estimate the maturity term without predetermining the factors that cause the risk premium to change over time. This feature can be particularly useful for investigating the possibility that short-term interest rates are affected by factors that can be difficult to observe, such as the political climate. This feature also raises interesting questions about the relative importance of the risk premium, which changes over time, in determining the maturity structure form, what changes in the risk premium are covered, which can be explained by changes in interest rate volatility and other economic and political factors, whether the risk premium is ever negative, and whether the risk premium will behave similarly within the maturity structure. It also helps us respond. 


\section{Emprical Findings}

In this study, the maturity structure of the interest is handled in terms of $\mathrm{BH}$, and the time-varying risk premium is estimated using the Kalman filter. Thanks to this method used, it is possible to estimate the factors that cause the risk premium to change over time, without being determined beforehand. The resulting risk premium estimation contains important information in terms of inflation expectations and risk perceptions of market participants and policy makers.

The time-varying risk premium for the interest rate was estimated using the Kalman filter. Considering the general structure of the Turkish economy, it is not surprising that the risk premium takes positive values in some periods and negative values in others. Due to the problems in the country's economy, intense fund outflows in various periods led to an increase in interest rates; these developments caused the risk premium to be realized as negative.

In the study, the risk premium estimates obtained by using the Kalman filter take positive values in some periods and negative values in other periods. Increases in risk in financial markets during periods of economic growth do not prevent investors from continuing their investments in return for an additional risk premium (positive risk premium). In periods of significant declines in economic growth, due to the increase in the risk level, investors quickly turn to alternative investment instruments (negative risk premium). While the investor may demand a higher return for investment instruments with higher risk in periods when the risk is positive; In periods when the risk is negative, risky investment instruments will be more sensitive to the negative risk premium than less risky ones, and they will be able to obtain lower returns as the risk increases.

\section{Discussion and Conclusion}

The most important feature of the study is that it provides how we can predict the factors that cause the risk premium for the Turkish economy to change over time, with the Kalman filter, without any predetermination. According to the risk premium estimates obtained by using the Kalman filter, the risk premium takes positive values in some periods and negative values in other periods. The risk premium is estimated to be negative in periods of high volatility and positive in periods of low volatility. The estimation results obtained provide rational investors with important and useful information about the uncertainties of future changes in interest rates.

The fact that the subject includes economic, social, political and behavioral dimensions along with the prevailing uncertainties in the field of study reduces the probability of a single hypothesis to be absolutely correct.

It is suggested that using the State-Space model and Kalman filter estimation method used in the study is more effective in estimating such time-dependent parameters, since the expected results cannot be obtained in the analyzes based on traditional approaches due to various reasons. 